\title{
Partitioning the effect of composition and diversity of tree communities on leaf litter decomposition and soil respiration
}

\author{
Mark Davidson Jewell, Bill Shipley, Etienne Low-Décarie, Cornelia M. Tobner, Alain Paquette, \\ Christian Messier and Peter B. Reich
}

M. D. Jewell and B. Shipley (bill.shipley@usherbrooke.ca), Dépt de Biologie, Univ. de Sherbrooke, 2500 boul. de l'Université, Sherbrooke, QC, J1K 2R1, Canada. - E. Low-Décarie, School of Biological Sciences, Univ. of Essex, Wivenhoe Park, Colchester, Essex, UK. - C. M. Tobner, A. Paquette and C. Messier, Center for Forest Research, Univ. du Québec à Montréal (UQÀM), Centre-ville station, Montreal, Quebec, Canada. CM also at: Inst. des sciences de la Foret Feuillue Tempérée (ISFORT), Univ. du Québec en Outaouais (UQO), Ripon, Quebec, Canada. - P. B. Reich, Dept of Forest Resources, Univ. of Minnesota Twin Cities, St. Paul, Minnesota, USA, and: Hawkesbury Inst. for the Environment, Western Sydney Univ., Richmond, Australia.

\begin{abstract}
The decomposition of plant material is an important ecosystem process influencing both carbon cycling and soil nutrient availability. Quantifying how plant diversity affects decomposition is thus crucial for predicting the effect of the global decline in plant diversity on ecosystem functioning. Plant diversity could affect the decomposition process both directly through the diversity of the litter, and/or indirectly through the diversity of the host plant community and its affect on the decomposition environment. Using a biodiversity experiment with trees in which both functional and taxonomic diversity were explicitly manipulated independently, we tested the effects of the functional diversity and identity of the living trees separately and in combination with the functional diversity and identity of the decomposing litter on rates of litter decomposition and soil respiration. Plant traits, predominantly leaf chemical and physical traits, were correlated with both litter decomposition and soil respiration rates. Surface litter decomposition, quantified by mass loss in litterbags, was best explained by abundance-weighted mean trait values of tree species from which the litter was assembled (functional identity). In contrast, soil respiration, which includes decomposition of dissolved organic carbon and root respiration, was best explained by the variance in trait values of the host trees (functional diversity). This research provides insight into the effect of loss of tree diversity in forests on soil processes. Such understanding is essential to predicting changes in the global carbon budget brought on by biodiversity loss.
\end{abstract}

Differences between the rates of net primary production and decomposition largely determine the dynamics of forest carbon sequestration in undisturbed forests. Decades of research have produced the consensus that primary productivity generally increases with producer diversity in a variety of systems (Cardinale et al. 2012, Balvanera et al. 2014). Although less studied, there is also evidence that taxonomic richness of the litter itself affects its rate of decomposition (Gartner and Cardon 2004, Hättenschwiler et al. 2005, Gessner et al. 2010, Handa et al. 2014), including in treedominated systems (Potvin et al. 2011, Hulvey et al. 2013) although this evidence is contradicted by other studies (Srivastava et al. 2009, Cardinale et al. 2011). Therefore, changes in the number of plant species in a community could impact rates of cycling of carbon and nutrients both by modulating production and decomposition.

Predicting the effect of plant diversity on changes in the soil carbon stock and fluxes requires an understanding of which measures and components of diversity most affect decomposition and soil respiration. First, diversity can be measured either in terms of the number of species present, or in terms of the phenotypic (functional) traits that these species possess. In regards to functional traits, both their means and variability can potentially affect decomposition processes. Finally, diversity, either taxonomic or functional, can be a property of both the plant litter undergoing decomposition, or of the host plant community, which would influence the biophysical environment in which this process occurs.

\section{Taxonomic diversity, functional diversity and functional identity}

Although species diversity ('taxonomic richness') is a commonly used metric, it is generally thought not to capture the full affect of diversity on ecosystem processes (Hooper et al. 2002, Cardinale et al. 2012). It is more likely that the functional properties of plants directly influence ecosystem functioning while the relationship with taxonomic richness arises because increasing taxonomic richness generally coincides with more variation in the traits of the component species. There are two main functional properties of plant 
communities that should be distinguished: the average values of plant properties expressed by the component plants ('functional identity'), and the variability of such properties between the component plants ('functional diversity') around these means. Grime's (1998) mass-ratio hypothesis states that the contribution of each species to an ecosystem process should be proportional to its abundance. Garnier et al. (2004) reformulated this hypothesis in terms of community-weighted mean trait values (CWM) explicitly relating functional trait means to ecosystem processes. Functional identity can then be calculated as a CWM trait value as the product of the average trait value of each species and its relative abundance, summed across all species in a community.

CWM traits of leaves can be used to scale up from species to communities to predict decomposition rates of litter mixtures (Garnier et al. 2004, Cortez et al. 2007, Quested et al. 2007, Kazakou et al. 2009, Tardif and Shipley 2013), including woody species used in the present study (Holdsworth et al. 2012). Litter mixtures having CWMs of leaf traits associated with fast resource uptake and rapid plant growth often exhibit accelerated decomposition. Monospecific litter decomposition rates are strongly controlled by litter quality determined by physical and chemical traits of living leaves (Swift et al. 1979, Aerts 1997, Cornwell et al. 2008) such as leaf dry matter content and the amounts of nitrogen, different carbon fractions (soluble carbon, cellulose, hemicellulose, lignin) and secondary compounds in the litter.

The effect on decomposition of litter functional diversity remains more elusive. Litterbag experiments comparing mixed-species decomposition rates to those of the monocultures of the component species commonly document interactions between species that lead to non-additive decomposition dynamics in mixtures (Wardle et al. 1997, Gartner and Cardon 2004, Tardif and Shipley 2013). However the direction and magnitude of these interactions are difficult to predict. Meta-analyses have revealed that synergistic and antagonistic interactions are equally common (Srivastava et al. 2009, Cardinale et al. 2011). Several mechanisms have been proposed to explain these synergistic and antagonistic effects of litter-mixing on decomposition including the transfer of nitrogen between litter types alleviating decomposer nutrient limitation (Handa et al. 2014), the release of secondary compounds such as polyphenols and tannins that retard decomposition, increased physical microhabitat complexity and interactions across trophic levels between decomposers, meso- and macro-fauna (Hättenschwiler et al. 2005). There is growing evidence that litter functional diversity may indeed increase terrestrial decomposition rates by providing a more stoichiometrically heterogeneous substrate for decomposers and detritivores (Hättenschwiler and Jørgensen 2010, Hättenschwiler et al. 2011).

\section{Litter composition and host environment}

The effect of plant functional properties on litter decomposition can be broken down into two components: 1) the functional properties of the litter, and 2) the functional properties of the living host plant community under which the litter decomposes (Fig. 1). This second component has rarely been studied in a fully controlled experimental context but our experimental design allowed us to separate and test these two potential effects on leaf litter decomposition. For instance, impacts of the living plant community on the soil microenvironment could influence litter decomposition by affecting the abundance or composition of the soil decomposers, either directly or indirectly via effects on the physical soil microenvironment (Hobbie et al. 2006). Furthermore, in an experimental context that manipulated only tree species composition, Jewell et al. (2015) showed that the same monoculture litter decomposed $10 \%$ faster in its host tree community of origin than in other communities (the home-field advantage).

In order to control for variation in soil conditions and environmental factors, the vast majority of studies investigating the decomposition of mixed-species litter have either been common garden or laboratory microcosm experiments, both of which isolate only the direct effect of litter diversity and exclude the indirect effects of the plant host community on the decomposition microenvironment. Differing composition and/or diversity of the host plant community could influence the decomposition microenvironment in a number of ways. Plant species identity and diversity have been shown to influence the composition of communities of soil bacteria (Stephan et al. 2000, Grüter et al. 2006), fungi (Bell et al. 2009) and macro-fauna (Wardle et al. 2006, Cesarz et al. 2007) that in turn drive decomposition rates (Gessner et al. 2010). By increasing long-term nutrient input and belowground physical complexity, above-ground plant diversity may promote below-ground decomposer/ detritivore diversity (Stephan et al. 2000, Zak et al. 2003, Balvanera et al. 2006, Aubert et al. 2010, Scherber et al. 2010) which could further influence decomposition rates through resource-use complementarity or other interactions of decomposers and detritivores. Furthermore, if plant diversity increases both above-ground and below-ground plant productivity, increased leaf and root litter input to the soil, an important source of carbon for soil invertebrates (Pollierer et al. 2007), could subsidize a larger invertebrate and microbial biomass and increase decomposition rates. Some studies have found increased microbial biomass or soil respiration with increasing plant diversity (Chung et al. 2007, Eisenhauer et al. 2010).

Relatively few studies exist which explicitly test the indirect effect of the diversity of the host plant community on litter decomposition but, consistent with theoretical predictions, nearly all report a positive effect (Hector et al. 2000, Knops et al. 2001, Carney and Matson 2005, Chapman and Koch 2007, Vivanco and Austin 2008, Scherer-Lorenzen 2008, Barantal et al. 2011). There is a strong bias in these studies towards herbaceous species. Despite the fact that forests contribute around $90 \%$ of global soil respiration (Bond-Lamberty and Thomson 2010), the effect of host tree diversity on microenvironmental conditions that affect decomposition is largely unknown.

\section{Surface litter decomposition and soil respiration}

Litterbag experiments are the most common method of quantifying litter decomposition but they can produce biased estimates of natural decomposition rates by isolating 


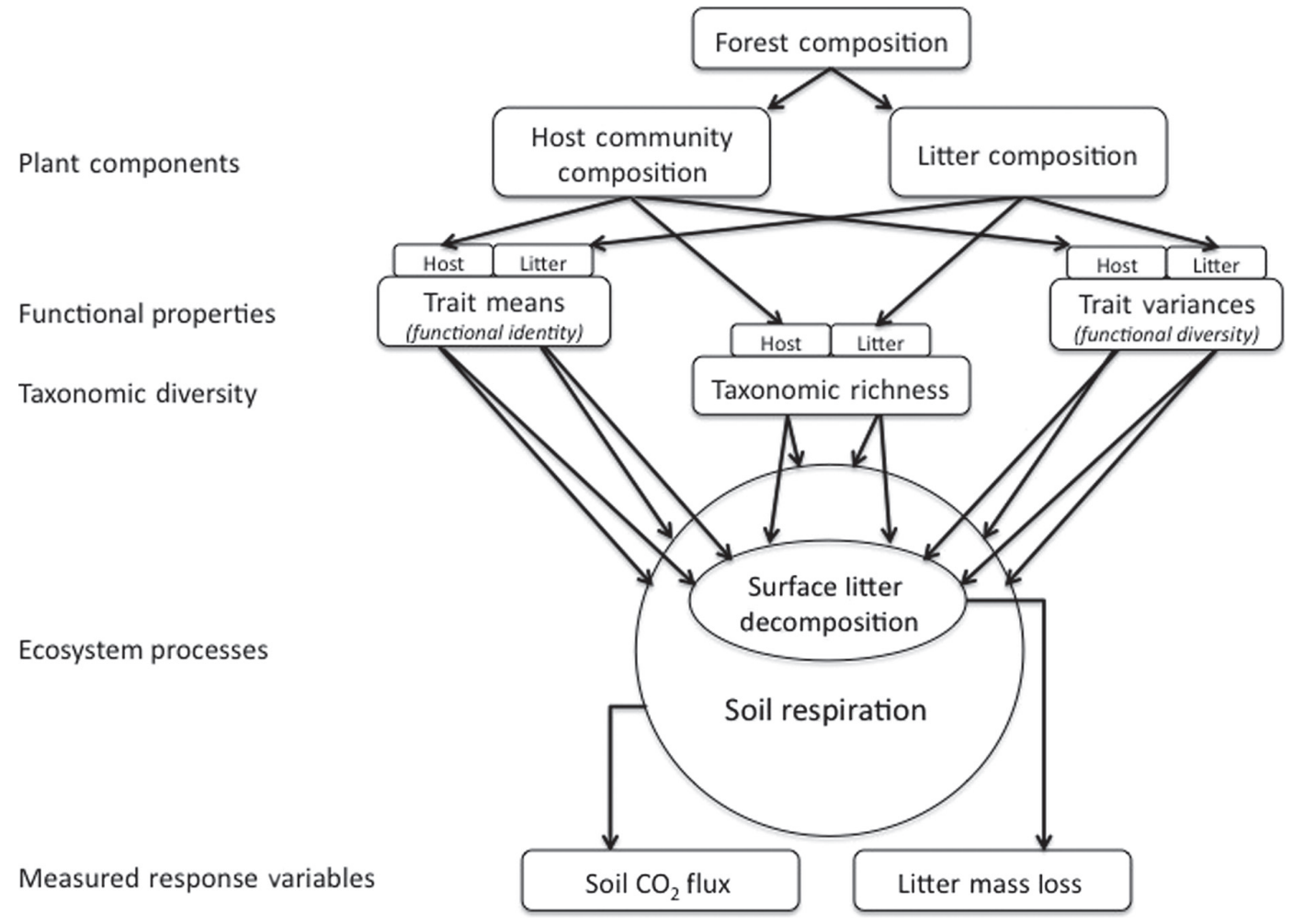

Figure 1. A partition of the possible effects of plant community structure on surface litter decomposition and soil respiration. Namely, plant components are broken into those of the host plant community and of the decomposing litter. Two different ecosystem processes were measured: surface litter decomposition by litter mass loss and soil respiration by soil $\mathrm{CO}_{2}$ flux. Surface litter decomposition isolates early rapid decay rates of litter, whereas soil respiration is a more global measurement of several processes including decomposition and root respiration.

only a fraction of the entire decomposition process. Early stages of decomposition are characterized by rapid mass loss from the breakdown of soluble and labile compounds; whereas later stages are characterized by the much slower breakdown of recalcitrant compounds, structural polymers and fibers (Melillo et al. 1989, Coûteaux et al. 1995). Litterbag experiments rarely last for longer than a season or two, capturing early rapid decay rates, whereas litter continues to breakdown for several more years, often following much slower trajectories (Harmon et al. 2009). Similarly, the further break down and assimilation of fine particulate matter after litter particles have left the litterbag is excluded from decomposition estimates using litterbags. Measuring soil carbon flux on the other hand captures decomposition processes (heterotrophic respiration) more broadly, including these latter stages of litter and other soil organic matter decomposition, but also includes root respiration (autotrophic respiration). We use both approaches, litterbags to estimate surface litter decomposition, and $\mathrm{CO}_{2}$ flux to estimate soil respiration, which allow us to harness their respective strengths to produce a more complete understanding of the decomposition process and how it is influenced by diversity.

Using a diversity experiment with trees, we tested the effects of tree diversity and identity on decomposition processes. Furthermore, by manipulating the decomposing litter and the host tree communities independently, we were able to evaluate the relative importance of each aspect of tree diversity on these processes. More specifically, we asked five main questions:

Q1. Does the taxonomic richness of the litter and/or host tree community increase rates of litter decomposition?

Q2. Are functional components of diversity better predictors of litter decomposition than taxonomic richness?

Q3. Are the average values (functional identity) of plant traits calculated as community-weighted means better predictors of litter decomposition than their variances (functional diversity)?

Q4. Does increasing diversity of the host tree community increase decomposition rates independently from the diversity of the decomposing litter?

Q5. Do the same aspects of diversity control both surface litter decomposition (measured as mass loss) and soil respiration (measured as soil $\mathrm{CO}_{2}$ flux)?

\section{Methods}

We used an experimental design involving a multi-year biodiversity experiment with tree species that manipulated functional tree diversity independently from taxonomic richness. We performed two litterbag experiments and a bulk soil respiration experiment to assess the effect of composition (diversity and identity) of tree communities on decomposition. 1) The 'home litter' experiment measured the decomposition rate of litter that was produced by its own host 
community; i.e. where the species represented in the litter were the same as those present as trees. Because both the litter and the host tree community matched, this experiment measured the combined effect of litter properties (diversity or identity) and those of the host trees on litter decomposition. In addition to measurement of mass loss in litterbags, we also measured rates of soil respiration. 2) The 'common litter mixture' experiment measured the decomposition rate of a single, common litter mixture decomposing in litterbags in different host tree communities. This experiment isolated the effect of the diversity and identity of the host community.

\section{Experimental site}

The experiment, a part of the 'International Diversity Experiment Network with Trees (IDENT)' (described in Tobner et al. 2014, Jewell et al. 2015) which is part of TreeDivNet (Verheyen et al. 2016) was located at McGill University (Sainte-Anne-de-Bellevue, Quebec, Canada, $45^{\circ} 5^{\prime} \mathrm{N}$, $\left.73^{\circ} 9^{\prime} \mathrm{W}\right)$. The experiment was established in spring 2009 on a former agricultural field that had been intensively cultivated for several decades. In general, one-year old angiosperm and two-year old gymnosperm seedlings from a species pool of 12 North American temperate tree species (Supplementary material Appendix Table A1) were used to create 37 different tree communities, each replicated in four blocks. Each $\sim 4 \times 4 \mathrm{~m}$ tree community consisted of 64 closely grown individual trees $(50 \mathrm{~cm}$ spacing). This design allowed the tree community to rapidly occupy fully both above and belowground environments. Each tree community was separated by $\sim 1.25 \mathrm{~m}$ corridors to reduce interactions between communities and allow movement of personnel and equipment without disturbing the plots. These corridors were trenched with a $30 \mathrm{~cm}$ incision during the summer in 2011 and 2012 to prevent roots from neighboring communities from interacting. Species combinations were chosen in order to create two independent gradients of taxonomic richness and functional diversity (Tobner et al. 2014). To detect potential effects of functional diversity while holding taxonomic richness constant, communities were established with large and comparable gradients of functional diversity within each level of taxonomic richness. At the beginning of the present experiment (spring 2012, i.e. three years after initial planting), individuals (averaged by species across all plots) varied in height from $1.32 \mathrm{~m}$ (Picea glauca) to $4.14 \mathrm{~m}$ (Betula papyrifera) and the above-ground space was fully occupied. Each block consisted of 12 monoculture communities, 14 twospecies mixtures, ten four-species mixtures and one twelvespecies mixture. Component species of each mixed-species community were planted in equal frequency. Community locations within a block, as well as individual tree locations within a community were randomized, the latter with restrictions to prevent the clumping of species and to maintain the same diversity in both the outside perimeter row (i.e. a buffer) and the inside $6 \times 6$ tree grid. Communities were regularly weeded manually to keep them free of any plant competition. This allowed the soil ecosystem to be only influenced by the planted tree species. All species (including conifers) produced enough naturally senesced leaf litter to sample for decomposition experiments.

\section{Surface litter decomposition using mass loss in litterbags}

\section{Home litter experiment: combined effect of litter composition and host system}

Recently senesced leaf litter for each of the 12 species was collected in the experiment's monoculture plots in midOctober 2011, immediately dried at $60^{\circ} \mathrm{C}$ for three days to stop decomposition processes, and then stored in the dark at $2^{\circ} \mathrm{C}$. For a given tree community, we then constructed litter mixtures consisting of an equal dry mass of each component species to have an overall mass of $2.0 \mathrm{~g}$ regardless of the number of species included. These mixtures were placed in fiberglass mesh $(2 \mathrm{~mm})$ litterbags $(15 \times 15 \mathrm{~cm})$. Petioles were removed from the leaves prior to weighing and not included in the bags. Litterbags were placed in the experimental tree communities in mid-April 2012. In each block, four identical litterbags to be destructively harvested at four different dates were placed in each tree community with the corresponding species combination directly onto the soil surface. In total there were 592 litterbags ( 4 blocks $\times 37$ communities/block $\times 4$ bags/community). Each litterbag was placed in the center of a square created by four trees. Location within tree communities was chosen at random from the 25 possible sites after the outer perimeter was excluded. Macro- and meso-fauna including earthworms and mites were observed inside litterbags.

Litterbags were destructively harvested over a single growing season after 28, 59, 124 and 184 days of incubation. Upon harvesting, samples were first gently washed to remove soil and then immediately dried at $60^{\circ} \mathrm{C}$ for 3 days to prevent further decomposition. Bags were then opened to remove all contamination and the remaining leaf litter was weighed. Percent dry mass remaining was calculated for each individual bag. Decomposition rates $\left(k\right.$ in $\left.\mathrm{g} \mathrm{g}^{-1} \mathrm{~d}^{-1}\right)$ were estimated for each of the four blocks of each tree community. This was done by fitting the least-squares regression slope of $\ln (\%$ dry mass remaining $(t))$ on time, thus assuming a negative exponential decay of dry mass (Olson 1963). This resulted in $37 \times 4=148$ independent estimates of $k$ for home litter.

\section{Common litter mixture experiment: effect of host system}

The common litter mixture experiment focused on the indirect effects of the live tree community, removing the effect of litter composition by using a common litter mixture containing equal parts dry mass Acer saccharum, Acer rubrum, Quercus rubra and Betula papyrifera. By including a combination of litter species with a diversity of physical and chemical traits we expected to increase the likelihood of observing resource use complementarity among decomposers and detritivores due to a larger total niche space (potentially decreasing niche overlap) and increased physical microhabitat diversity. Litter was collected as for the home litter experiment. This common litter mixture was placed in all monoculture and four-species tree communities ( 22 of the 37 total communities). Litterbags were constructed, installed and harvested, and decomposition rates estimated following the same proto$\mathrm{col}$ as the home litter experiment. In total there were 352 litterbags ( 4 blocks $\times 22$ communities [12 monoculture 
communities +10 four-species mixtures]/block $\times 4$ bags $/$ community). This resulted in $22 \times 4=88$ independent estimates of $k$ for common litter.

\section{Soil respiration as $\mathrm{CO}_{2}$ flux}

Soil $\mathrm{CO}_{2}$ flux was measured using the closed-chamber technique (Rolston 1986) with a portable infrared gas analyzer. One series of flux measurements was taken for each tree community in each block, using the same sampling design as described in the home litter experiment. One location was randomly chosen per community per block, leaves and debris were cleared away and a $372 \mathrm{ml}$ chamber was placed directly on a $100 \mathrm{~cm}^{2}$ patch of soil surface. $\mathrm{CO}_{2}$ evolution was measured over an 8 -min period with readings taken every $30 \mathrm{~s}$. One block was measured per day, with the order of communities within blocks randomly selected to discount for any effect of time and environmental conditions. All measurements were taken between 11 and 14 July 2012, during a period without rain, and with a $10.5^{\circ} \mathrm{C}$ range in air temperature during measurements. $\mathrm{CO}_{2}$ flux was modeled with an exponential function based on simple diffusion theory as described by Nakano et al. (2004). $\mathrm{CO}_{2}$ flux values $\left(\mathrm{mol} \mathrm{CO} \mathrm{m}^{-2} \mathrm{~s}^{-1}\right)$ were estimated as the slope of a leastsquare linear regression of $\log$ of chamber headspace $\mathrm{CO}_{2}$ concentrations over the $\log$ of time for the 8-min period (ie.16 time intervals). This was done for each block and community, resulting in 148 estimates of $\mathrm{CO}_{2}$ flux.

\section{Trait measurements}

We measured physical traits of living leaves and chemical traits of newly senesced leaf litter for each species growing in monoculture. Water-saturated leaf dry matter content and specific leaf area of living leaves were measured using a standardized protocol (Garnier et al. 2001). Average values were calculated for each species from 36 measurements: 3 leaves from 3 individuals from 4 blocks. Total litter carbon and nitrogen contents of newly senesced leaves were measured by high temperature combustion $\left(960^{\circ} \mathrm{C}\right)$ followed by thermo-conductometric detection using an elementar multi-element analyzer. Average values for each species were calculated from three replicate measurements of ground and mixed plant material collected from numerous individuals in all blocks. Values for a set of an additional 11 morphological, chemical and growth traits were obtained for each species from published sources (Paquette and Messier 2011). These were maximum height, growth rate, leaf size, wood density, wood decay resistance, root habit, root diameter, (living) leaf nitrogen and carbon contents, leaf longevity and leaf mass per area.

\section{Calculation of functional diversity and community- weighted traits}

Although it is generally thought that functional diversity should yield more informative results than taxonomic richness in biodiversity-ecosystem functioning research, there is no consensus on how functional diversity should be measured (Laliberté and Legendre 2010, Schleuter et al. 2010, Villéger et al. 2008). To test the hypotheses that plant functional diversity increases decomposition rates we calculated several diversity indices a priori, and to help identify mechanisms responsible for these biodiversity effects, we developed indices a posteriori using the trait combinations that best predicted decomposition.

We used Laliberté and Legendre's (2010) functional dispersion index (FDis) that measures multivariate functional diversity as an abundance-weighted pair-wise distance between species traits, which is closely related to the commonly used Rao's quadratic entropy (Rao 1982). Since all of our traits are continuous variables and we used the Euclidean distance, FDis reduces to the sum of the community-weighted variances of each trait (Eq. 1) as defined in Shipley (2010, p. 170); here $t_{i j}$ is the value of trait $j$ in species $\mathrm{i}, \bar{t}_{j}$ is the community-weighted mean value of trait $j$ and $p_{j}$ is the relative abundance of species $i$ in the mixture. Just as a community-weighted mean trait is the trait value expressed by an average individual in a community, a community-weighted variance is the (squared) distance of an average individual in a community from the communityweighted trait value.

$$
\text { FDis }=\sum_{j=1}^{T} \sum_{i=1}^{S} p_{i}\left(t_{i j}-\bar{t}_{j}\right)^{2}
$$

To capture the effects of both litter diversity and that of the host community on decomposition processes, we calculated functional dispersion using five different a priori combinations of traits, (see Supplementary material Appendix Table A2 for summary of our indices).

CWMs of traits were calculated for each community in each block as the product of the average trait value of a species and its relative abundance in the community, summed across all species in the community. Species' relative abundance in communities (used to calculate both CWMs and functional diversity) was obtained as a proportion of the total aboveground abundance based on 2012 stem volumes (tree height $\times$ diameter $^{2}$ at $5 \mathrm{~cm}$ ).

\section{Statistical analysis}

\section{Calculation of predicted values and 'DFPs'}

We calculated predicted values of mixture decomposition rates based on the litter types decomposing in monoculture (Fig. 2). If $k_{i}$ is the monoculture decomposition rate of species $i$ and $p_{i j}$ is its relative abundance in litter mixture $j$, then the predicted decomposition rate in mixture $j,\left(\widehat{k}_{j}\right)$ implied by the mass-ratio hypothesis is $\hat{k}_{j}=\sum_{i} k_{i} p_{i j}$. These predicted values therefore assume no interactions between species (litter types decompose identically whether in monoculture or mixtures and the total effect is strictly additive) and serve as a null hypothesis when testing for a diversity effect (nonadditive). We calculated these predicted decomposition rates for all litter mixtures of our home litter experiment from monocultures, and calculated predicted soil $\mathrm{CO}_{2}$ fluxes in all mixed-species communities using the same approach. We also calculated predicted decomposition rates of the common litter mixture in each mixed species tree community from the common litter mixture decomposing in the component monoculture tree communities. These predicted values were calculated separately for each block to maintain 


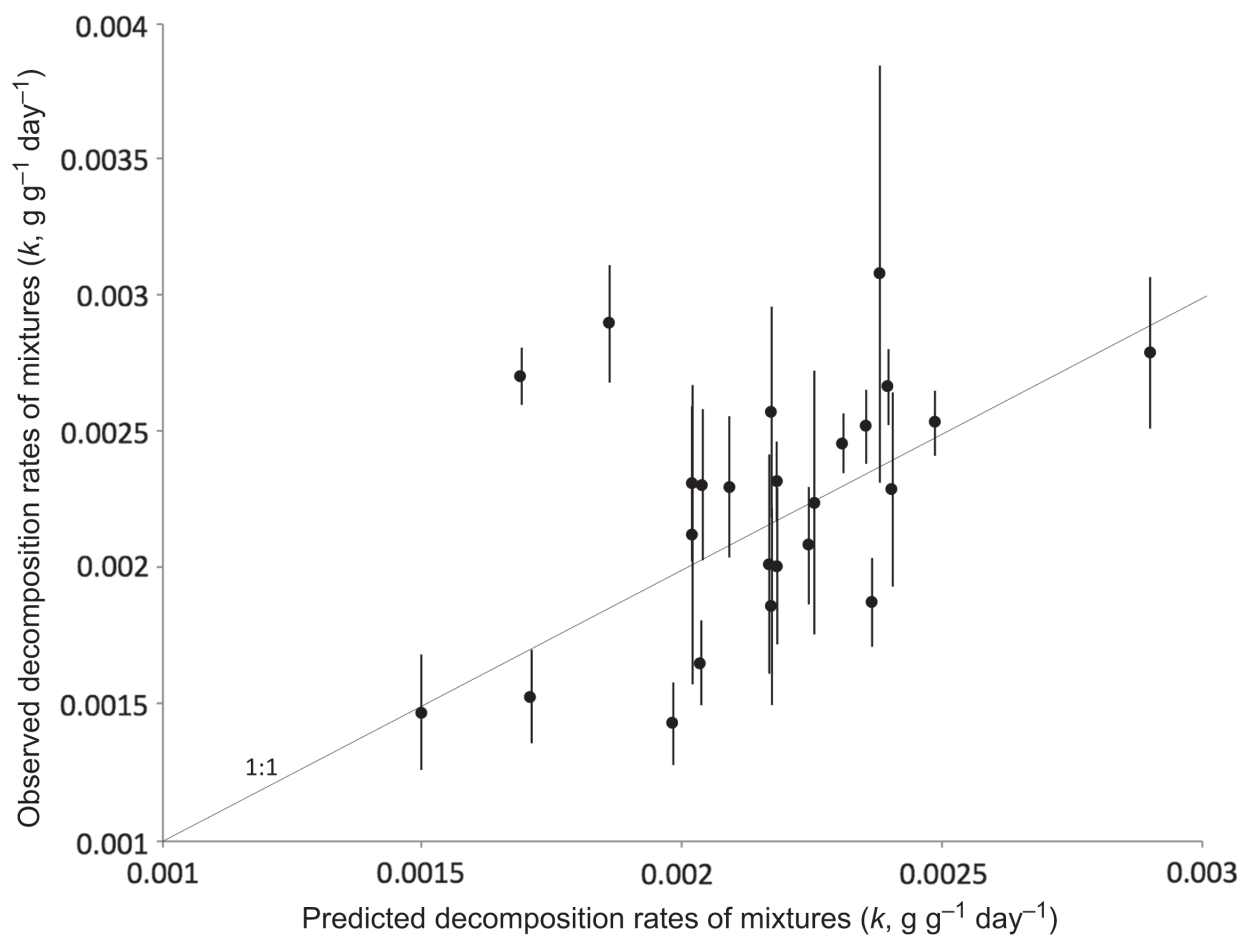

Figure 2. Observed values of decomposition rate $(k)$ in mixed-species communities (2,4 and 12) as a function of the values predicted by the mass-ratio hypothesis calculated using decomposition rates of leaves from individual species (ie. community-weighted means). Each point is the average of four replicates \pm SE. Points above the 1:1 line imply synergistic interactions between species whereas points below the 1:1 line imply antagonistic interactions.

statistical independence. For all mixed-species communities in all blocks, and for each response variable (home litter $k$, common litter mixture $k$, and soil $\mathrm{CO}_{2}$ flux) the deviance from the predicted (DFP) value was calculated as the difference between predicted and observed values (which is akin to testing for overyielding in BEF experiments). Hence, a positive DFP value indicates synergistic species interactions and a negative DFP value indicates antagonistic interactions.

\section{Statistical tests}

We used ANOVAs with community identity as the single factor to test if there were differences in either $k$-values or $\mathrm{CO}_{2}$ flux rates between communities for both decomposition experiments and for $\mathrm{CO}_{2}$ flux. Because our common-litter mixture experiment only had two levels of host community taxonomic richness (1 and 4), and since the DFP value of a monoculture is necessarily zero, we determined if the mixture decomposed faster in the four-species communities than would be predicted from monocultures by comparing the overall average DFP value of four-species communities to the null hypothesis of DFP value $=0$ using a one-sample, one-tailed t-test. In the home litter experiment, we had different communities within each level of taxonomic richness. We therefore fitted mixed model regressions with the calculated $\mathrm{CO}_{2}$ flux or $k$-value of each block of each community as the dependent variable, the taxonomic richness of the community as the fixed factor, and community identity as the random factor, to test the effect of taxonomic richness on home litter decomposition and $\mathrm{CO}_{2}$ flux. Intercepts were allowed to vary between communities but slopes were fixed. A fixed slope estimate different from zero was evidence that these dependent variables changed with taxonomic richness.
Identical mixed-model regressions were performed to test the effect of functional diversity on home litter decomposition and $\mathrm{CO}_{2}$ flux. Since values of functional diversity are zero for monocultures, these communities were excluded from all analyses testing the effect of functional diversity. To test if functional diversity increased $k$-values and $\mathrm{CO}_{2}$ flux independently of taxonomic richness, we fitted identical mixed model regressions within each level of taxonomic richness. To identify the relative contribution of different traits (through their variances) to a biodiversity effect, we performed stepwise deletion of explanatory traits in a regression model. As in the previous analysis, community identity was included as a random factor. An identical procedure of stepwise deletion was used to test the effect of CWM traits on our response variables. Block was initially included in all mixed models as a random factor, but was in all cases nonsignificant and so was removed. Values of 'marginal $\mathrm{R}^{2}$ ', the proportion of the variance explained by the fixed factor alone (Nakagawa and Schielzeth 2013), were calculated for each fixed factor of our mixed-models.

To assess the predominance of non-additive effects in litter mixtures for the home litter experiment, we compared the average DFP value of each mixture to the null hypothesis $(\mathrm{DFP}=0)$ with a two-tailed t-test, using the values from the four blocks as replicates. This gave 25 separate $t$-values (i.e. 25 multi-species communities). We used a Bonferonni correction, giving a significance level of 0.002 . To test if these differences between the observed decomposition rates of the mixed-species communities and those predicted by the massratio hypothesis were on average synergistic or antagonistic, we compared the overall average DFP value to zero using a one-sample, two-tailed t-test. We used a two-sample 
two-tailed t-test to test if DFP values in four-species communities were different from those in two-species communities. The same tests were performed for soil $\mathrm{CO}_{2}$ flux.

All statistics and figures were generated with $\mathrm{R}$ ver. 3.0.2 (<www.r-project.org >). Linear regressions were performed using the $1 \mathrm{~m}$ function and mixed model regressions using the lmer function in the lme 4 package of R (Bates and Sarkar 2006).

\section{Data deposition}

Data available from the Dryad Digital Repository: <http:// dx.doi.org/10.5061/dryad.292c8> (Jewell et al. 2016).

\section{Results}

\section{Common litter mixture}

Our common litter mixture experiment was designed to isolate the effect of the diversity of the host community on the decomposition microenvironment by manipulating only the composition of the tree community and its associated decomposition microenvironment while keeping the litter mixture fixed. This common litter mixture then decomposed in all monoculture and four-species tree communities $(22$ communities in total, replicated four times). By the end of the experiment (184 days), remaining litter dry mass (averaged by block) ranged from $47.3-76.1 \%$ of initial values, with a mean of $59.3 \%$. The decomposition rates of this single litter mixture differed between tree communities (ANOVA, common litter mixture decomposition as function of host community composition, $\mathrm{F}_{21,66}=2.14, \mathrm{p}=0.01$ ) showing that the composition of the tree community affected litter decomposition rates (as there were no differences in the litter itself). The common litter decomposed slightly faster on average in the ten four-species tree communities than would be predicted from the same mixture decomposing in component monoculture tree communities $\left(9 \%\right.$ faster, $t_{9}=1.63$, $\mathrm{p}=0.06)$.

\section{Home litter}

Our home litter experiment combined the effects of the diversity of both the litter and of the host tree community on the decomposition process by decomposing each unique litter mixture in its own natural tree community. This experiment involved monoculture, two-species, four-species and 12 -species communities. By the end of the experiment, remaining litter dry mass (averaged by block) ranged from $50.1-80.2 \%$ of initial values, with a mean of $64.5 \%$ (similar to the common litter experiment). There was a significant difference in decomposition rates between the 37 communities (ANOVA, decomposition as function of community composition, $\left.\mathrm{F}_{36,111}=2.47, \mathrm{p}=0.0002\right)$.

\section{Effect of diversity on decomposition}

These differences between communities were however not convincingly related to our a priori measures of diversity. Taxonomic richness did not affect litter decomposition rates based on the mixed-model regression (fixed slope of decomposition on richness $=1.38 \times 10^{-5}, \quad t_{109}=0.33$, $\mathrm{p}=0.74)$ nor were any of our a priori indices of functional diversity related to decomposition (Supplementary material Appendix Table A3). When the variability of each functional trait was tested separately using linear regression, we found a strong positive effect of variability in litter nitrogen content on decomposition rates (slope of decomposition on $\mathrm{FD}_{\mathrm{N}}$ for the 25 communities with multiple species $=7.08 \times 10^{-4}$, $\left.\mathrm{t}_{74}=3.71, \mathrm{p}=0.0004\right)$.

The average difference between observed decomposition rates and those predicted assuming additivity of all mixtures did not differ significantly from $0\left(t_{24}=1.36\right.$, $p=0.18$ ) indicating that overall, litter mixtures did not decompose faster or slower than what would be predicted from monocultures. Furthermore, detectable non-additivity of species effects was rare (Fig. 2). Only three of the 25 DFP values of the mixtures were significantly different from 0 at the $5 \%$ level using separate t-tests with blocks serving as replicates and, using a Bonferonni correction, none differed significantly from zero.

\section{Effect of functional identity on decomposition}

Decomposition of litter in its home community was however related to several CWMs of litter traits (Table 1). Since many traits were strongly correlated with each other, we simplified a multiple regression model until all traits obtained significance. Decomposition rates were positively correlated with CWM litter nitrogen content (slope of decomposition rate on CWM litter nitrogen accounting for community composition for 37 different communities $=9 \times 10^{-5}$, $\left.\mathrm{t}_{109}=4.00 \mathrm{p}=0.0001\right)$ and negatively correlated with CWM litter carbon content (slope $=-1 \times 10^{-5}, \mathrm{t}_{109}=5.46$ $\mathrm{p}=3 \times 10^{-7}$ ), with these two traits together explaining $27 \%$ of the total variation (Fig. 3).

\section{Soil $\mathrm{CO}_{2}$ flux}

\section{Effect of tree diversity on soil respiration}

Soil $\mathrm{CO}_{2}$ flux increased both with tree taxonomic richness (Fig. 4) based on the mixed-model regression

Table 1. Effect of community weighted means (CWM) and variances (FD) of traits on rates of litter decomposition and soil respiration in the home litter experiment. Significant effects are represented with arrows.

\begin{tabular}{|c|c|c|c|c|}
\hline \multirow[b]{2}{*}{ Functional trait } & \multicolumn{2}{|c|}{ Litter mass loss } & \multicolumn{2}{|c|}{ Soil $\mathrm{CO}_{2}$ flux } \\
\hline & CWM & $\mathrm{FD}$ & CWM & FD \\
\hline Litter nitrogen content & $\nearrow$ & $\nearrow$ & & $\nearrow$ \\
\hline Litter carbon content & $\searrow$ & & & $\nearrow$ \\
\hline Leaf nitrogen content & $\bar{\nearrow}$ & & & $\nearrow$ \\
\hline Leaf mass area & $\searrow$ & & & $\nearrow$ \\
\hline Leaf dry matter content & & & & \\
\hline Specific leaf area & $\nearrow$ & & & $\nearrow$ \\
\hline Leaf size & $\nearrow$ & & & $\nearrow$ \\
\hline Leaf longevity & & & & \\
\hline Max height & & & & $\nearrow$ \\
\hline Growth rate & & & $\searrow$ & \\
\hline Wood density & $\nearrow$ & & & $\nearrow$ \\
\hline Wood decay resistance & $\searrow$ & & & $\nearrow$ \\
\hline Root habit & & & & $\nearrow$ \\
\hline Root diameter & $\searrow$ & & & \\
\hline
\end{tabular}




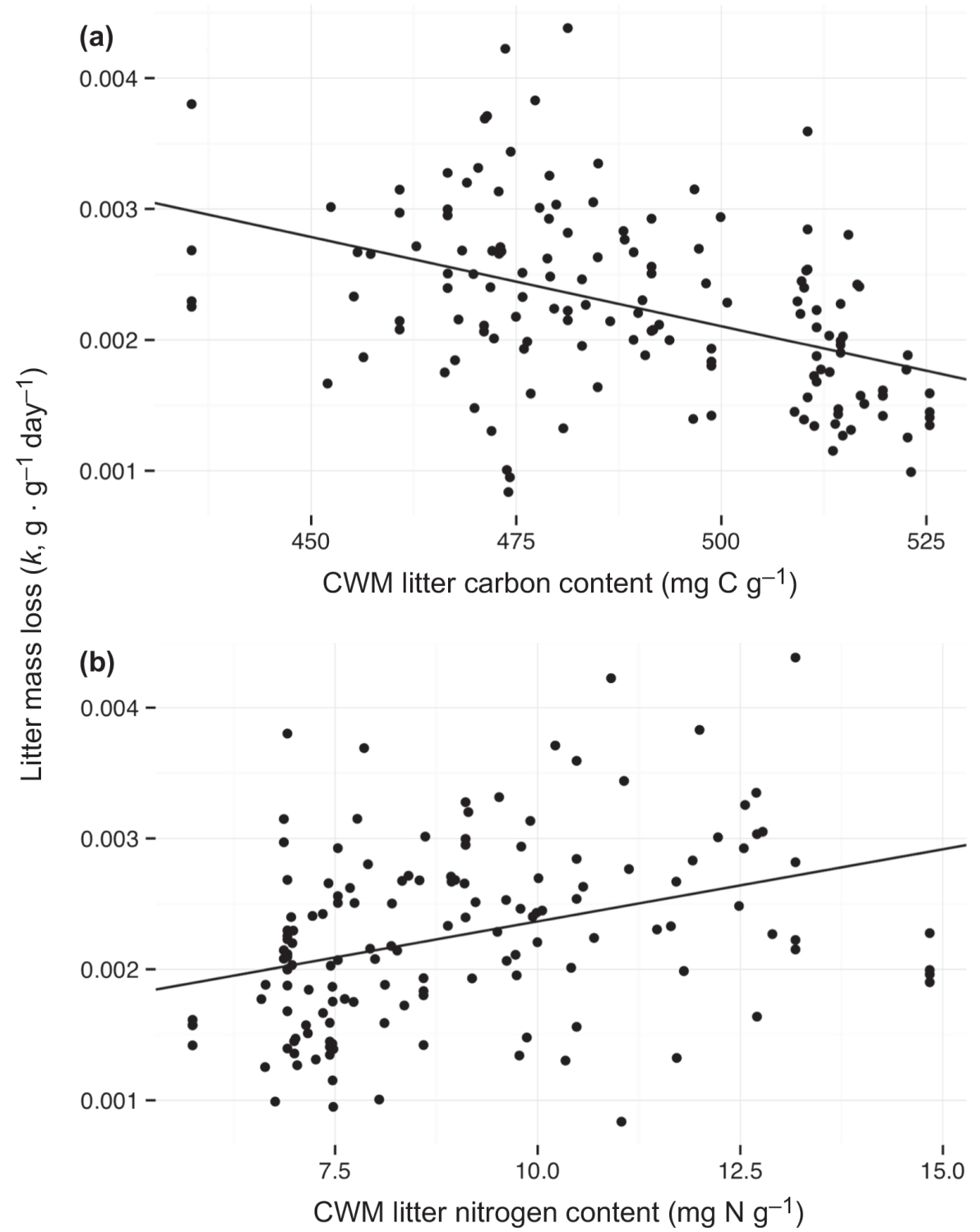

Figure 3. Correlations between community-weighted mean (CWM) traits and decomposition rates of natural litter in all communities. (a) Decomposition rates significantly decreased with community-weighted mean litter carbon content $(\mathrm{p}<0.001)$ and $(\mathrm{b})$ increased with community-weighted mean litter nitrogen content $(\mathrm{p}<0.001)$ (from mixed model multiple regression, marginal $\mathrm{R}^{2}=0.27$ ).

(slope $\left.=1.32 \times 10^{-4}, \mathrm{t}_{109}=2.75, \mathrm{p}=0.007\right)$, and with all but one of our a priori indices of functional diversity (all but index $\mathrm{V}$ based on roots traits, Supplementary material Appendix Table A3). Over the $1-4$ species range, $\mathrm{CO}_{2}$ flux increased by $1.65 \times 10^{-4} \mathrm{~mol} \mathrm{CO} \mathrm{Cm}^{-2} \mathrm{~s}^{-1}$ per species added, (an $8.2 \%$ increase per species from monoculture rates.) On average, two-species communities had flux rates $4 \%$ higher, four-species $26 \%$ higher, and 12 -species $23 \%$ higher than monocultures (Fig. 4, note median presented in figure). The average DFP value of all mixtures was significantly greater than 0 (mean $=0.0003, \mathrm{t}_{24}=4.09, \mathrm{p}=0.0002$ ) indicating an overall presence of synergistic interactions between tree species in their effect on soil $\mathrm{CO}_{2}$ flux. Furthermore, these synergistic interactions increased in strength with diversity, as DFP values increased with several a priori indices of functional diversity (Supplementary material Appendix Table A4), and were greater for four-species communities than for two-species communities $\left(t_{21}=2.52, \mathrm{p}=0.02\right)$. To identify the traits responsible for this biodiversity effect we tested the effect of functional diversity on soil $\mathrm{CO}_{2}$ flux for each trait separately. Increasing diversity of several litter and tree traits increased rates of soil $\mathrm{CO}_{2}$ flux (Table 1). As with CWM traits, we simplified a multiple regression model until all remaining traits were significant. This resulted in only two traits, variation in litter initial nitrogen content and maximum tree height, that best explained soil $\mathrm{CO}_{2}$ flux in our multiple regression.

To evaluate which aspect of diversity had a stronger effect on $\mathrm{CO}_{2}$ flux, we compared our best performing functional diversity index (using only variation in litter initial nitrogen content and maximum tree height) with taxonomic richness using two regression models of $\mathrm{CO}_{2}$ flux on each type of diversity. The taxonomic richness model used all 37 communities, whereas the functional 


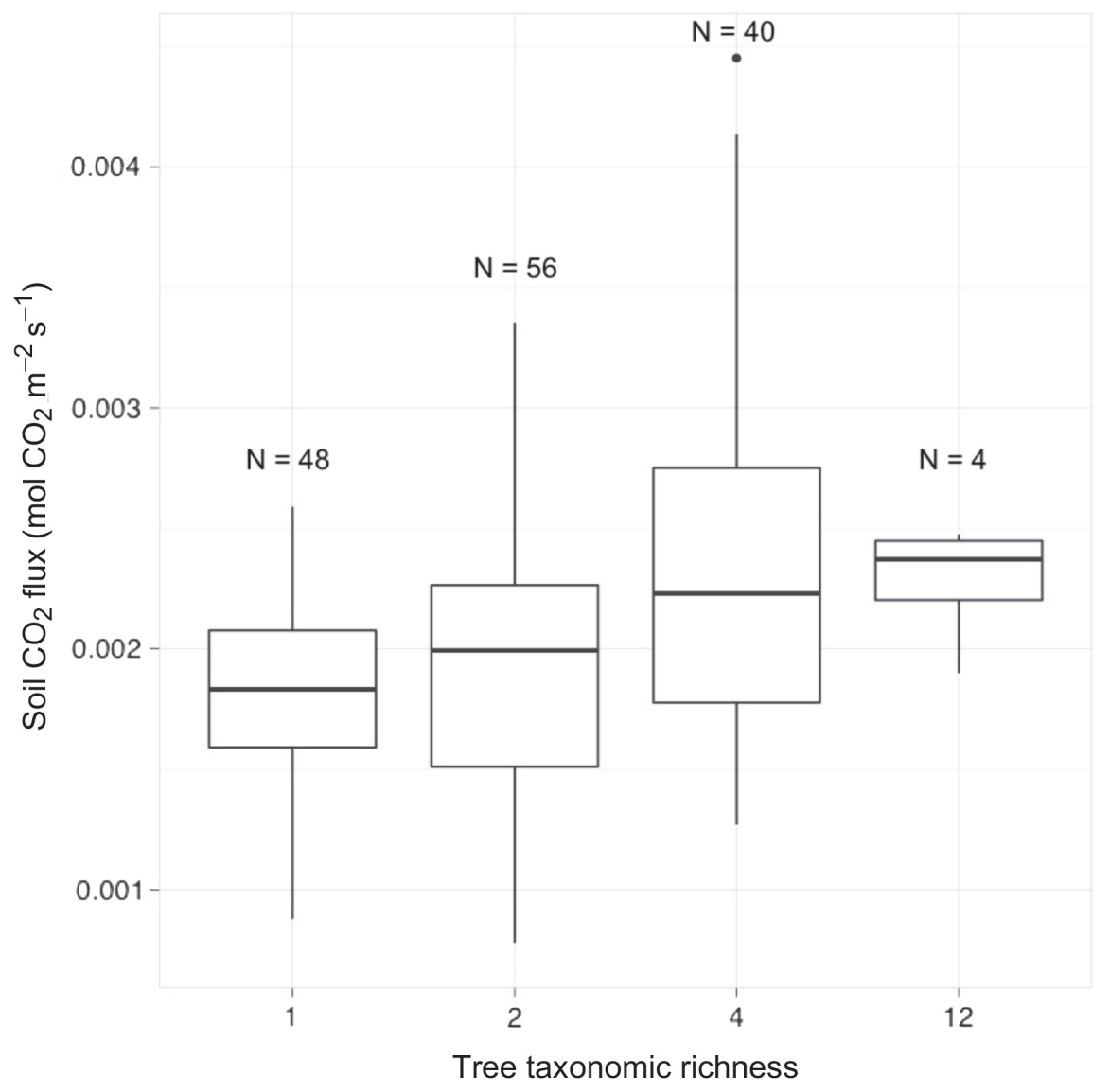

Figure 4. Soil $\mathrm{CO}_{2}$ flux increases with tree taxonomic richness. The upper and lower hinges of the box correspond to the first and third quartiles and the band inside marks the median. The whiskers extend from the hinge to the highest and lowest values that are within $1.5 \times \mathrm{IQR}$ of the hinge, where IQR is the inter-quartile range, or distance between the first and third quartiles. Data beyond the end of the whiskers are outliers and plotted as points.

diversity model used only the 25 mixed-species communities given that functional diversity of monocultures is 0 . Functional diversity had a larger effect on $\mathrm{CO}_{2}$ flux than did taxonomic richness (slopes $=5.82 \times 10^{-4}$ versus $1.32 \times 10^{-4}$, t-test comparing the two slopes $\mathrm{t}_{(100+148-4)}=$ $3.77, \mathrm{p}=0.0001)$ and was more strongly correlated with $\mathrm{CO}_{2}$ than taxonomic richness (marginal $\mathrm{R}^{2}=0.16$ versus 0.07 ). We next tested the effect of functional diversity on soil $\mathrm{CO}_{2}$ flux within each level of taxonomic richness. Soil $\mathrm{CO}_{2}$ increased with increasing functional diversity (again using our best performing index) for two-species communities (fixed slope $=5.67 \times 10^{-4}, t_{42}=3.69$, $p=0.0006$ ), but not for four-species communities (fixed slope $\left.=3.25 \times 10^{-4}, \mathrm{t}_{30}=0.95, \mathrm{p}=0.35\right)$.

\section{Effect of functional identity on soil $\mathrm{CO}_{2}$ flux}

Soil $\mathrm{CO}_{2}$ flux was correlated with only one of the 14 CWM traits, i.e. tree growth rate, (slope $=-2.06 \times 10^{-4}$, $\left.\mathrm{t}_{109}=2.49, \mathrm{p}=0.01\right)$. Since this correlation was weak (marginal $\mathrm{R}^{2}=0.07$ ), in the opposite direction of that provided in our a priori hypothesis, and since we can expect to find one significant correlation by chance for every 20 traits tested, we treat this result with caution. However, although fast plant relative growth rate is often associated with high litter quality and therefore rapid decomposition (Garnier and Navas 2012), a negative correlation between tree growth rate and soil respiration has also already been reported (Orwin et al. 2010).

\section{Discussion}

\section{Host community diversity and litter diversity}

We found some marginally significant evidence suggesting that taxonomic richness of the host tree community increased decomposition rates of a common litter mixture. However, when litter diversity and that of the host tree community were combined in the home litter experiment, this diversity effect (if truly present) was lost, as we observed no effect of overall plant taxonomic richness on decomposition rates. Observed decomposition rates of litter mixtures did not differ from rates predicted when assuming additive effects of decomposition rates of individual components of the litter, either overall (i.e. when averaged across mixtures) or on average within mixtures. This suggests that litter mixtures in their home host community decompose in a way predictable from monoculture decomposition, supporting Grime's mass-ratio hypothesis (Grime 1998).

The majority of mixed-species litterbag decomposition experiments in the literature present idiosyncratic (equally positive and negative) effects of litter taxonomic richness 
on decomposition. These idiosyncrasies may be related to experimental methods as most of these experiments isolated the effect of litter diversity while ignoring the possible effect of the diversity of the host plant community. The few studies that do include or isolate the effect of the host community on litter decomposition most often report a positive effect of host diversity on decomposition (Hector et al. 2000, Knops et al. 2001, Carney and Matson 2005, Chapman and Koch 2007, Vivanco and Austin 2008, Scherer-Lorenzen 2008, Barantal et al. 2011). Our results are consistent with these trends, suggesting that if plant species do act synergistically to increase litter decomposition, it is likely at the level of the host community affecting decomposition conditions as opposed to the litter itself.

The effect of host community taxonomic richness differed between surface litter decomposition and total soil respiration. First, we detected clear positive effects of taxonomic richness on the rate of soil respiration. Second, we found clear evidence of non-additive synergistic effects. Increasing the number of tree species in an experimental community increased the magnitude of these synergistic effects. Since the different tree communities were initially established on a common homogenized agricultural soil with randomization and blocking, and were kept free of plant competition, we can confidently ascribe the effect to taxonomic richness rather than to pre-existing differences in the soil or the impact of other plants.

\section{Taxonomic and functional diversity}

\section{Surface litter decomposition}

Our home litter litterbag experiment showed no effect of litter taxonomic richness on surface litter decomposition rates. However, increasing chemical diversity of the litter mixture, namely the variability of initial nitrogen content of leaves in the litter, increased decomposition rates. The important component of diversity was not the number of species but rather the phenotypic diversity of senesced tissues of the species present in the bag. The importance of variability in initial nitrogen content of leaf litter for decomposition may be explained by the presence of nitrogen transfer between litter types which has been suggested as an important mechanism of synergistic litter-mixing effects (Hättenschwiler et al. 2005, Gessner et al. 2010). When litter with varying nitrogen status decomposes in mixture, nitrogen from high quality litter can be transferred either passively (by leaching) or actively (by fungal hyphae) to lower quality litter, alleviating decomposer nutrient limitation and stimulating overall decomposition rates (Wardle et al. 1997, Schimel and Hättenschwiler 2007, Tiunov 2009). Meta-analyses compiling more than 80 studies report idiosyncratic effects of litter taxonomic richness on decomposition rates in terrestrial systems (Srivastava et al. 2009, Cardinale et al. 2011), whereas three of the five studies that tested the effect of litter chemical diversity on litter mass loss in terrestrial ecosystems report a positive diversity effect (Meier and Bowman 2008, 2010, Hättenschwiler and Jørgensen 2010, Barantal et al. 2011, Holdsworth et al. 2012). Our results are consistent with these previously published findings. The relationship between litter taxonomic richness and litter chemical diversity can be positive, negative or idiosyncratic depending on the identity of the species included in the litter mixture (Epps et al. 2007). It is then perhaps not surprising that litter chemical diversity (with its direct link to synergistic mechanisms) and not taxonomic richness would increase decomposition rates.

\section{Soil respiration}

In contrast to surface litter decomposition, we found a clear effect of tree taxonomic richness on soil respiration. As we hypothesized, functional diversity further increased $\mathrm{CO}_{2}$ flux and was a better predictor than was taxonomic richness. All of our a priori indices of functional diversity, except that based on root traits, were positively correlated with soil $\mathrm{CO}_{2}$ flux (Supplementary material Appendix Table A3). Interestingly, the a priori index that best predicted $\mathrm{CO}_{2}$ flux was the index that included only litter chemical traits, the same index that most accurately explained litter mass loss. Testing the effect of functional diversity, one trait at a time, the diversity of 10 of the 14 available traits significantly increased soil $\mathrm{CO}_{2}$ flux rates (Table 1). The traits whose variances had the strongest effects on soil $\mathrm{CO}_{2}$ flux were all chemical and physical traits of litter and leaves, in contrast to root and structural traits. However, given that root and structural traits were obtained from databases and not directly measured, we don't completely disregard their potential importance. This suggests that repeated litter input to the soil is likely the main mechanism by which tree diversity increases soil respiration. Since leaf litter represents a major portion of energy and nutrients available to the decomposer community, and since leaf/litter functional traits determine litter quality, these traits capture important above-below ground interactions. Whereas plant taxonomic identity and the presence of key functional groups has traditionally been understood as the most important biotic determinants of soil biota community structure (Wardle et al. 2006, Wardle 2006), recent evidence suggests that plant taxonomic diversity, may be equally or more important (Eisenhauer et al. 2011a). A functionally diverse litter input with a large variation in chemi$\mathrm{cal}$ and physical properties has the potential to support both increased microbial activity and diversity by diversifying both trophic and spatial resources for decomposers (Hooper et al. 2000) and several experiments using experimental grasslands have reported increased microbial and faunal diversity and activity with increasing plant diversity (Chung et al. 2007, Eisenhauer et al. 2010, 2011a, b, Scherber et al. 2010, Sabais et al. 2011).

There is a wide range of estimates within and across systems of the relative contributions of individual processes to total soil $\mathrm{CO}_{2}$ flux (Raich and Schlesinger 1992, Subke et al. 2006), with recent studies indicating a range of autotrophic contributions lower than 20\% (Rodeghiero et al. 2013 ) to a contribution of over $40 \%$ of soil carbon flux (Carbone et al. 2016). Litter decomposition may not be the dominant below ground process or source of soil $\mathrm{CO}_{2}$, as roots may be the main source of carbon for soil invertebrates (Pollierer et al. 2007). Given that increased plant taxonomic richness often leads to increased aboveground biomass production, and that increased aboveground biomass would likely result in increased root biomass, it is possible that the increased soil $\mathrm{CO}_{2}$ flux we report was actually driven, not by increased soil organic matter decomposition, 
but by increased root respiration or respiration of root exudate, which can represent $1 / 5$ of root associated respiration (Kuzyakov 2002). To investigate the potential of biodiversity acting through root processes to affect soil $\mathrm{CO}_{2}$ flux, we referred to the work of Archambault (2015), who measured root biomass in the same experimental plots in the same field season, and found that root density in the first $40 \mathrm{~cm}$ in the monocultures, two- and four-species mixtures was $0.81,0.73$ and $0.78\left(\mathrm{mg} \mathrm{cm}^{-3}\right)$ respectively. In other words, there was no difference in root density with increasing tree taxonomic richness. In a regression of soil $\mathrm{CO}_{2}$ flux on root density, using root density data reported in Archambault (2015), we found no relationship between the two variables $\left(\mathrm{F}_{1,34}=1.148, \mathrm{R}^{2}=0.033, \mathrm{p}=0.292\right)$. Root density and associated respiration do not seem to play an important role in linking soil $\mathrm{CO}_{2}$ flux and tree diversity, and therefore, the strong effect of tree diversity on soil respiration is more likely due to an increase in the decomposition of soil organic matter rather than an increase in root respiration. Certainly, this conclusion must remain tentative since we know little about the differences in specific root respiration rates. Furthermore, our results indicating that tree taxonomic richness increases the decomposition of a common litter mixture suggest there was indeed increased decomposer/detritivore activity in more taxonomically diverse tree communities.

Increased plant diversity could increase levels of litter and SOM decomposition both by increasing the rates of these processes per quantity of litter input, or by increasing primary productivity and therefore overall litter input to the soil. Tobner et al. (2016), working in the same experiment at the same time, found that most mixtures did not differ in productivity from the averages of their respective monocultures, (but some did overyield significantly). We therefore tentatively attribute the increased soil respiration to faster decomposition rates.

\section{Functional identity and functional diversity}

\section{Surface litter decomposition}

Whereas decomposition was poorly related to diversity and found to be positively correlated with variance in only one trait (litter initial nitrogen content,) decomposition was related to several trait specific CWMs (Table 1). The majority of these leaf traits are part of the leaf economic spectrum (Reich et al. 1997, Wright et al. 2004), a suite of traits that capture fundamental tradeoffs in plant resource-use strategy, which has been shown to be related to decomposition rates (Garnier et al. 2004, Cortez et al. 2007, Quested et al. 2007). Testing the means and variances of these traits together in a multiple regression we identified CWM litter carbon and nitrogen concentrations as the two most important traits. Our litterbag experiment shows that although the diversity of both the host community and of the litter can increase decomposition rates, it is the mean values of litter traits that best explain surface litter decomposition.

\section{Soil respiration}

The opposite trend was found with respect to soil respiration since the diversity of tree and litter traits increased rates of soil $\mathrm{CO}_{2}$ flux, and not the CWMs of these traits. Given that the trees in our experiment were young, it is likely that they had not had time to exhibit their full potential impact on the soil system. Working experimentally with trees poses several constraints and tradeoffs are inevitable. However, by planting trees at high density and removing all other plants, we accelerated the importance of interactions between individuals, thus maximizing the potential to find a diversity effect. While the effects of functional properties of the decomposing litter on decomposition rates are manifested immediately, the effect of the trees on the decomposition environment should strengthen over time as they grow in size and as effects accumulate over the years. We therefore predict that the observed effects of host tree diversity on the decomposition microenvironment and on soil respiration should increase as the system matures.

\section{Comparing responses of soil respiration and surface litter decomposition}

Both mass loss in litterbags and soil respiration $\left(\mathrm{CO}_{2}\right.$ flux) can inform us about different components of the complete decomposition process. On the one hand, mass loss in litterbags is dominated by the mechanical breakdown of surface litter and leaching of compounds during the earlier stage of decomposition, but misses the subsequent decomposition of smaller litter particles and dead roots. In contrast, soil $\mathrm{CO}_{2}$ flux (on bare soil) captures the decomposition of fine particulate matter, dead roots, and leachate that has already entered the soil (some predating the experiment), but is also affected by processes like root respiration (autotrophic respiration) that are not related to decomposition (heterotrophic respiration). Given the different processes captured by litter bags (surface litter decomposition) and soil $\mathrm{CO}_{2}$ flux (heterotrophic respiration associated with later stages of decomposition and autotrophic respiration), it may be expected that they respond differently to different elements of forest diversity including different functional properties (i.e. communityweighted means and functional diversity) of the litter and host communities.

For both surface litter decomposition and for soil respiration, we found that chemical and physical leaf and litter traits were the most important. For early stages of surface litter decomposition, the means of these trait values were more important than their variances. However, for soil respiration, the contrary was true. For surface litter decomposition, species complementarity is likely to be less important, so long as there are sufficient amounts of highly labile compounds remaining. Initial litter chemistry is thus more important than diversity. We attribute the strong effect of tree diversity on soil respiration to the impact of a diverse litter input on the soil biota. Despite having been determined a research priority more than 15 years ago in the biodiversity-ecosystem functioning research program (Hooper et al. 2000), the effect of plant diversity on belowground community structure and diversity is still poorly understood. To better understand the mechanisms behind the complementarity of plant species not only on decomposition and soil $\mathrm{CO}_{2}$ flux, but also on productivity, more work is needed linking plant diversity to properties of the soil decomposer community. 
Acknowledgements - We would like to thank the numerous people that have helped establish and maintain the experiment and to McGill's MacDonald campus staff for their support and the use of the land. Laura Williams kindly provided the SLA trait data and Chelsea Archambault and Tanya Handa the root density data. Funding - Funding for this project was provided by NSERC RDC and DISCOVERY grants.

\section{References}

Aerts, R. 1997. Climate, leaf litter chemistry and leaf litter decomposition in terrestrial ecosystems: a triangular relationship. - Oikos 79: 439-449.

Archambault, C. 2015. Effet de la diversité spécifique et fonctionnelle des arbres sur la densité et profondeur d'enracinement [Effect of taxonomic and functional diversity of trees on the density and depth of roots]. - MS thesis, Univ. du Québec à Montréal, Canada.

Aubert, M. et al. 2010. Aboveground-belowground relationships in temperate forests: plant litter composes and microbiota orchestrates. - For. Ecol. Manage. 259: 563-572.

Balvanera, P. et al. 2006. Quantifying the evidence for biodiversity effects on ecosystem functioning and services. - Ecol. Lett. 9: 1146-1156.

Balvanera, P. et al. 2014. Linking biodiversity and ecosystem services: current uncertainties and the necessary next step. - BioScience 64: 49-57.

Barantal, S. et al. 2011. Long-term presence of tree species but not chemical diversity affect litter mixture effects on decomposition in a neotropical rainforest. - Oecologia 167: 241-252.

Bates, D. and Sarkar, D. 2006. lme4: linear mixed-effects models using S4 classes. - R package ver. 0.99875-8 < http://CRAN.Rproject.org $>$.

Bell, T. et al. 2009. Microbial biodiversity and ecosystem functioning under controlled conditions and in the wild. - In: Biodiversity, ecosystem functioning and human wellbeing: an ecological and economic perspective. Oxford Univ. Press, pp. 121-133.

Bond-Lamberty, B. and Thomson, A. 2010. Temperature-associated increases in the global soil respiration record. - Nature 464: 579-582.

Carbone, M. S. et al. 2016. Constrained partitioning of autotrophic and heterotrophic respiration reduces model uncertainties of forest ecosystem carbon fluxes but not stocks. - J. Geophys. Res. Biogeosci. 121, doi:10.1002/ 2016JG003386.

Cardinale, B. J. et al. 2011. The functional role of producer diversity in ecosystems. - Am. J. Bot. 98: 572-592.

Cardinale, B. J. et al. 2012. Biodiversity loss and its impact on humanity. - Nature 486: 59-67.

Carney, K. M. and Matson, P. A. 2005. Plant communities, soil microorganisms and soil carbon cycling: does altering the world belowground matter to ecosystem functioning? - Ecosystems 8: 928-940.

Cesarz, S. et al. 2007. Earthworm communities in relation to tree diversity in a deciduous forest. - Eur. J. Soil Biol. 43: S61-S67.

Chapman, S. K. and Koch, G.W. 2007. What type of diversity yields synergy during mixed litter decomposition in a natural forest ecosystem? - Plant Soil 299: 153-162.

Chung, H. et al. 2007. Plant species richness, elevated $\mathrm{CO}_{2}$, and atmospheric nitrogen deposition alter soil microbial community composition and function. - Global Change Biol. 13: 980-989.

Cornwell, W. K. et al. 2008. Plant species traits are the predominant control on litter decomposition rates within biomes worldwide. - Ecol. Lett. 11: 1065-1071.
Cortez, J. et al. 2007. Plant traits, litter quality and decomposition in a mediterranean old-field succession. - Plant Soil 296: $19-34$.

Coûteaux, M.-M. et al. 1995. Litter decomposition, climate and liter quality. - Trends Ecol. Evol. 10: 63-66.

Eisenhauer, N. et al. 2010. Plant diversity effects on soil microorganisms support the singular hypothesis. - Ecology 91: 485-496.

Eisenhauer, N. et al. 2011a. Plant diversity surpasses plant functional groups and plant productivity as driver of soil biota in the long term. - PloS ONE 6:e16055.

Eisenhauer, N. et al. 2011b. Positive relationship between herbaceous layer diversity and the performance of soil biota in a temperate forest. - Soil Biol. Biochem. 43: 462-465.

Epps, K. Y. et al. 2007. Chemical diversity - highlighting a species richness and ecosystem function disconnect. - Oikos 116: $1831-1840$

Garnier, E. and Navas, M.-L. 2012. A trait-based approach to comparative functional plant ecology: concepts, methods and applications for agroecology. A review. - Agron. Sustainable Devel. 32: 365-399.

Garnier, E. et al. 2001. A standardized protocol for the determination of specific leaf area and leaf dry matter content. - Funct. Ecol. 15: 688-695.

Garnier, E. et al. 2004. Plant functional markers capture ecosystem properties during secondary succession. - Ecology 85: 2630-2637.

Gartner, T. B. and Cardon, Z.G. 2004. Decomposition dynamics in mixed-species leaf litter. - Oikos 104: 230-246.

Gessner, M. O. et al. 2010. Diversity meets decomposition. - Trends Ecol. Evol. 25: 372-380.

Grime, J. P. 1998. Benefits of plant diversity to ecosystems: immediate, filter and founder effects. - J. Ecol. 86: 902-910.

Grüter, D. et al. 2006. Influence of plant diversity and elevated atmospheric carbon dioxide levels on belowground bacterial diversity. - BMC Microbiol. 6: 68.

Handa, I. T. et al. 2014. Consequences of biodiversity loss for litter decomposition across biomes. - Nature 509: 218-221.

Harmon, M. E. et al. 2009. Long-term patterns of mass loss during the decomposition of leaf and fine root litter: an intersite comparison. - Global Change Biol. 15: 1320-1338.

Hättenschwiler, S. and Jørgensen, H. B. 2010. Carbon quality rather than stoichiometry controls litter decomposition in a tropical rain forest. - J. Ecol. 98: 754-763.

Hättenschwiler, S. et al. 2005. Biodiversity and litter decomposition in terrestrial ecosystems. - Annu. Rev. Ecol. Evol. Syst. 36: 191-218.

Hättenschwiler, S. et al. 2011. Functional diversity of terrestrial microbial decomposers and their substrates. - Comptes Rendus Biol. 334: 393-402.

Hector, A. et al. 2000. Consequences of the reduction of plant diversity for litter decomposition: effects through litter quality and microenvironment. - Oikos 90: 357-371.

Hobbie, S. E. et al. 2006. Tree species effects on decomposition and forest floor dynamics in a common garden. - Ecology 87: 2288-2297.

Holdsworth, A. et al. 2012. Leaf litter disappearance in earthworm-invaded northern hardwood forests: role of tree species and the chemistry and diversity of litter. - Ecosystems 15: 913-926.

Hooper, D. U. et al. 2000. Interactions between aboveground and belowground biodiversity in terrestrial ecosystems: patterns, mechanisms, and feedbacks. - BioScience 50: 1049-1061.

Hooper, D. U. et al. 2002. Species diversity, functional diversity, and ecosystem functioning. - In: Biodiversity and ecosystem functioning - synthesis and perspectives. Oxford Univ. Press, pp. 195-207. 
Hulvey, K. B. et al. 2013. Benefits of tree mixes in carbon plantings. - Nat. Climate Change 3: 869-874.

Jewell, M. D. et al. 2015. A traits-based test of the home-field advantage in mixed-species tree litter decomposition. - Ann. Bot. 116: 781-788.

Jewell, M. D. et al. 2016. Data from: Partitioning the effect of composition and diversity of tree communities on leaf litter decomposition and soil respiration. - Dryad Digital Repository, < http://dx.doi.org/10.5061/dryad.292c8>.

Kazakou, E. et al. 2009. Litter quality and decomposability of species from a Mediterranean succession depend on leaf traits but not on nitrogen supply. - Ann. Bot. 104: 1151-1161.

Knops, J. M. H. et al. 2001. Biodiversity and decomposition in experimental grassland ecosystems. - Oecologia 126: 429-433.

Kuzyakov, Y. 2002. Separating microbial respiration of exudates from root respiration in non-sterile soils: a comparison of four methods. - Soil Biol. Biochem. 34: 1621-1631.

Laliberté, E. and Legendre, P. 2010. A distance-based framework for measuring functional diversity from multiple traits. - Ecology 91: 299-305.

Meier, C. L. and Bowman, W. D. 2008. Links between plant litter chemistry, species diversity and below-ground ecosystem funtion. - Proc. Natl Acad. Sci. USA 105: 19780-19785.

Meier, C. L. and Bowman, W. D. 2010. Chemical composition and diversity influence non-additive effects of litter mixtures on soil carbon and nitrogen cycling: implications for plant species loss. - Soil Biol. Biochem. 42: 1447-1454.

Melillo, J. M. et al. 1989. Carbon and nitrogen dynamics along the decay continuum: plant litter to soil organic matter. - Plant Soil 115: 189-198.

Nakagawa, S. and Schielzeth, H. 2013. A general and simple method for obtaining $\mathrm{R}^{2}$ from generalized linear mixed-effects models. - Meth. Ecol. Evol. 4: 133-142.

Nakano, T. et al. 2004. A comparison of regression methods for estimating soil - atmosphere diffusion gas fluxes by a closedchamber technique. - Soil Biol. Biochem. 36: 107-113.

Olson, J. S. 1963. Energy storage and the balance of producers and decomposers in ecological systems. - Ecology 44: 322-331.

Orwin, K. H. et al. 2010. Linkages of plant traits to soil properties and the functioning of temperate grassland. - J. Ecol. 98: 1074-1083.

Paquette, A. and Messier, C. 2011. The effect of biodiversity on tree productivity: from temperate to boreal forests. - Global Ecol. Biogeogr. 20: 170-180.

Pollierer, M. et al. 2007. The underestimated importance of belowground carbon input for forest soil animal food webs. - Ecol. Lett. 10: 729-736.

Potvin, C. et al. 2011. An ecosystem approach to biodiversity effects: carbon pools in a tropical tree plantation. - For. Ecol. Manage. 261: 1614-1624.

Quested, H. et al. 2007. Plant traits relate to whole-community litter quality and decomposition following land use change. - Funct. Ecol. 21: 1016-1026.

Raich, J. W. and Schlesinger, W. H. 1992. The global carbon dioxide flux in soil respiration and its relationship to vegetation and climate. - Tellus Ser. B 44: 81-99.

Rao, C. R. 1982. Diversity and dissimilarity coefficients: a unified approach. - Theor. Popul. Biol. 21: 24-43.

Reich, P. B. et al.1997. From tropics to tundra: global convergence in plant functioning. - Proc. Natl Acad. Sci. USA 94: 13730-13733.

Rodeghiero, M. et al. 2013. Components of forest $\mathrm{CO}_{2}$ efflux estimated from $\Delta^{14} \mathrm{C}$ values of soil organic matter. - Plant Soil 364: 55-68.

Supplementary material (available as Appendix oik-03868 at $<$ www.oikosjournal.org/appendix/oik-03868>). Appendix 1.
Rolston, D. E. 1986. Gas flux. - In: Method of soil analysis, Part 1. Physical and mineralogical methods, 2nd edn. Am. Soc. Agron. Soil Sci. Soc. Am., Madison, pp. 1103-1119.

Sabais, A. C. W. et al. 2011. Plant species richness drives the density and diversity of collembola in temperate grassland. - Acta Oecol. 37: 195-202.

Scherber, C. et al. 2010. Bottom-up effects of plant diversity on multitrophic interactions in a biodiversity experiment. - Nature 468: 553-556.

Scherer-Lorenzen, M. 2008. Functional diversity affects decomposition processes in experimental grasslands. - Funct. Ecol. 22: 547-555.

Schimel, J. P. and Hättenschwiler, S. 2007. Nitrogen transfer between decomposing leaves of different $\mathrm{N}$ status. - Soil Biol. Biochem. 39: 1428-1436.

Schleuter, D. et al. 2010. A user's guide to functional diversity indices. - Ecol. Monogr. 80: 469-484.

Shipley, B. 2010. From plant traits to vegetation structure. Chance and selection in the assembly of ecological communities. - Cambridge Univ. Press.

Srivastava, D. S. et al. 2009. Diversity has stronger top-down than bottom-up effects on decomposition. - Ecology 90: 1073-1083.

Stephan, A. et al. 2000. Plant diversity affects culturable soil bacteria in experimental grassland communities. - J. Ecol. 88: 988-998.

Subke, J-A. et al. 2006. Trends and methodological impacts in soil $\mathrm{CO}_{2}$ efflux partitioning: a metaanalytical review. - Global Change Biol. 12: 921-943.

Swift, M. J. et al. 1979. Decomposition in terrestrial ecosystems. - Univ. of California Press.

Tardif, A. and Shipley, B. 2013. Using the biomass-ratio and idiosyncratic hypotheses to predict mixed-species litter decomposition. - Ann. Bot. 111: 135-141.

Tiunov, A. V. 2009. Particle size alters litter diversity effects on decomposition. - Soil Biol. Biochem. 41: 176-178.

Tobner C. M. et al. 2014. Advancing biodiversity - ecosystem functioning science using high-density tree-based experiments over functional diversity gradients. - Oecologia 174: 609-621.

Tobner, C. M. et al. 2016. Functional identity is the main driver of diversity effects in young tree communities. - Ecol. Lett. 19: 638-647.

Villéger, S. et al. 2008. New multidimensional functional diversity indices for a multifaceted framework in functional ecology. - Ecology 89: 2290-2301.

Vivanco, L. and Austin, A.T. 2008. Tree species identity alters forest litter decomposition through long-term plant and soil interactions in Patagonie, Argentina. - J. Ecol. 96: 727-736.

Verheyen, K. et al. 2016. Contributions of a global network of tree diversity experiments to sustainable forest plantations. - AMBIO 45: 29-41.

Wardle, D. A. 2006. The influence of biotic interactions on soil biodiversity. - Ecol. Lett. 9: 870-886.

Wardle, D. A. et al. 1997. Biodiversity and plant litter: experimental evidence which does not support the view that enhanced species richness improves ecosystem function. - Oikos 79: 247-258.

Wardle, D. et al. 2006. The influence of plant litter diversity on decomposer abundance and diversity. - Soil Biol. Biochem. 38: $1052-1062$.

Wright, I. J. et al. 2004. The worldwide leaf economics spectrum. - Nature 428: 821-827.

Zak, D. R. et al. 2003. Plant diversity, soil microbial communities, and ecosystem function: are there any links? - Ecology 84: 2042-2050. 